\title{
Collective Unconscious and Characterization of Berenger as the Victim of Collective Unconscious
}

\author{
Shaqayeq Moqari, Nooshin Elahipanah \\ Semnan University of Iran, Iran \\ E-mail address: Moqari.sh2089@gmail.com \\ nelahipanah@semnan.ac.ir
}

Keywords: Collective Unconscious, Berenger, Victim, loneliness

\begin{abstract}
The present article is a study of character of Berenger in Ionesco's play the Rhinoceros. In fact he is a victim of collective unconscious. The collective unconscious is very significant in the psychology of Jung. It is generated and fashioned by us all. This indicates that it is in each of us like a massive container of the archetypes of the entire humanity. It is reachable by everyone. Berenger is different in the play from others. He does not act according to collective unconscious that many people share. When other characters act according to the norms of collective unconscious, Beregner does not, this makes him different from others and he stands and resists temptation. Others change to their animalistic form while he remains human. In fact, he is a victim of the collective unconscious which makes him suffer loneliness among crowd of people.
\end{abstract}

\section{INTRODUCTION}

The collective unconscious is a significant notion in the psychology of Carl Gustav Jung. The collective unconscious is generated and fashioned by us all. This indicates that it exists in each of us, a massive container of the archetypes of the entire humanity. It is reachable by everyone. Overall, the collective unconscious involves features that many people share and which each of us receive when we are born. Anxiety and pleasure, for instance are hereditary human features. They happen without conscious reasons but merely happen from internal need. These archetypes are the consequence of the many experiences of life that reiterate themselves: sunrise and sunset, the seasons, life and death, food, danger, and so on. They are signs for the experiences of human being. They are expressed in "myths, religion, dreams, and private fantasies, as well as in works of literature"(Abrams and Harpham, 1993: 16).

The content of the archetype is fundamentally insensible. It experiences a change when it becomes conscious or when it is being professed. The way it is changed is governed by the state of awareness of the person in which the archetype has arisen. An archetype is experienced as image and as emotion. It is principally recognizable in such characteristic and significant human circumstances as birth and demise, puberty, extreme fear or a terrible experience. Throughout such life phases and experiences archetypes will often happen obviously in dreams. The shape of the archetype is only incompletely determined. Its content is an original image that can only have form when it has become conscious, and accordingly has become filled with material from the conscious.

Consequently archetypes, when becoming conscious, will form themselves, for instance in stories and fairy tales, depending upon the cultural circumstances of the people. The fundamental content, though, is the same everywhere. Archetypes cannot be ignored and dismissed. They will continually display themselves. When a society experiences a change its appearances of the archetypes will transform too. They get another shape, another image in the frame. Archetypes by themselves are impartial, without value judgments given to them, but they can be understood in an optimistic, undesirable or impartial way.

In relation to the collective unconscious Jung has another term which is called individuation. By individuation Jung means that one becomes a person, an individual, a completely united character. He associate individuation with "objectivity and detachment from emotional ties"(Krapp, 2005: 208) It is a procedure of self-awareness during which one assimilates those contents of the psyche that have the capability to become conscious. It is a quest for entirety. It is an experience 
that could be expressed as the detection of the Providence in yourself, or the finding of the wholeness of your Self. This does not always occur without discomfort, but it is essential to admit many things that usually we would recoil from. Once a person has admitted the contents of his unconsciousness and has get to the objective of the individuation procedure, he is aware of his relations with everything that lives, with the whole universe.(ibid, 213)

Individuation is a normal, intrinsic process in man. It cannot be encouraged by something external, but it raises from the inside. Just as the body can become distorted or sick by absence of food or movement, the character can be distorted by absence of experience or instruction. Jung emphasizes that our contemporary world does not offer enough chance to experience the archetype of the Shadow. When a child displays his animal instincts, usually it is chastised by its parents. Chastisement does not bring about the death of the repressed tendencies, which is impossible, but it brings about the suppression of this archetype. The Shadow goes to an unconscious state, embryonic and undistinguishable. Then, when the Shadow breaks through the repressive barrier, and this does happen once in a while, it manifests itself in a sinister, pathological way. Jung did not deem individuation as equally possible or suitable for everyone. "It would . . . be a great mistake to suppose that this is the path every neurotic must travel. . . It is appropriate only in those cases where consciousness has reached an abnormal degree of development." He considers the individuation process as candidly elitist.(ibid, 213)

\section{DISCUSSION}

\section{Berenger a savior and a hero}

When questioned whether Berenger, the principal character in Rhinoceros, was thought to be considered as a dramatic exemplification of Ionesco himself, the writer answered demurely maybe there is some similarity there. Even the most superficial look at Ionesco's biography divulges outstanding resemblances between the dramatist and the character who would continue to intrigue and enrage audiences across the world. Like Ionesco, Berenger complains against ideologies, group-think and political slogans, being frightened by the power of the rhinoceroses and promising to fight them until the end.

Berenger appears in four of Ionesco.s plays: Rhinoceros, The Killer, Exit the King and $A$ Stroll in the Air. Applying the collective unconscious to this play and the situation of Berenger we have to separate Berenger from the rest of the characters as does the play itself. Therefore, he does not belong to a mass of people. This means that Berenger is a counter-collective unconscious figure, one who does not feed from this reservoir of what collective unconscious contains. Thereby he is a victim of the collective unconscious because he simply does not have it and does not do as a Roman does when in Rome. If conformity to the situation is a staple of the unconscious and every country has it and many cultures nourish it, here it is not the case with Berenger. Ionesco about the character of Berenger says:

Berenger finds himself alone in a dehumanised world where each person tried to be just like all the others. It is just because they all tried to be like each other that they became dehumanised, or rather depersonalised, which is after all the same thing. ${ }^{1}$

The problem is lack of conformity of the Berenger. Ionesco says 'It is the malady of conformity which knows no bounds, no boundaries..' all the characters in the play conform to the situation and become rhinoceroses. Berenger does not. He is a free man. He as he himself does say at the end of the play he does not 'capitulate'. He is what Ionesco want out of a hero like him, 'A free man should pull himself out of vacuity on his own, by his own efforts and not by the efforts of other people'. Berenge tries to teach people not to capitulate to the state of rhinoceros but no one is willing to do that. Like Berenge, Ionesco is teaching his readers not to go to the same direction that others go. Not to conform is in fact the individuation of Berenger. He becomes aware of himself, of

\footnotetext{
${ }^{1}$ www.royalcourttheatre.com/files/.../220/Rhinoceros
} 
his make-up, and the way to discover his true, inner self. His individuation is a function that allows him to distinguish himself from others and make sense of himself and his actions. It gives him a sense of uniqueness.

Berenger is individualistic and at the end comes to regret it but suddenly recognizes his mistake and undergoes his metamorphosis.

People who try to hang on to their individuality always come to a bad end! [He suddenly snaps out of it] Oh well, too bad I I'll take on the whole of them I I'll put up a fight against the lot of them, the whole lot of them 1 I'm the last man left, and Tm staying that way until the end. I'm not capitulating!(Ionesco, 2003: 107)

The end of the play is equal to maturity on the part of Berenger. He promises to defeat the entire of the group of rhinoceroses. That is why the playwright observes in Berenger a modern man., a character looking for spiritual vitality and freedom of choice, resistant to tyranny and repelled by conformity:

Berenger is, I hope, above all a character. And if he is time-resistant, it will be because he has proved himself as a character; he should, if he has any real worth, survive even after his message. Has become outdated. Poetically, it is not his thought but his passion and his imaginative life that will matter, for his message could quite as well be delivered now by a journalist,a philosopher or a moralist ${ }^{2}$.

Berenger may appear inactive, "a disheveled and malcontented member of his small town" (Valentine, 2011: 54) but his very unwillingness to make decisions, to be a leader, defends him against getting enmeshed in ideological skirmish that Ionesco stages in Rhinoceros. Certainly, his indecisiveness and irresoluteness and understanding ultimately become the source of a kind of power and ability.

Berenger's change is the proper metamorphosis in Rhinoceros. While the other characters bodily change into rhinoceroses, exemplifying the violent natures they had previously suppressed, Berenger's change is moral and completely opposite from his position at the start of the play. He starts as a purposeless, estranged everyman who drinks too much and who discovers little worth in life, but the beauty of Daisy, his colleague. He is jaded and tired by his work, too lethargic to culture himself, and asks himself whether life is a delusion and a dream - that is, if its illogicality is the artifact of a dream-like state of ridiculous logic, and if life, like a dream, is controlled by unconscious desires. Notwithstanding his entertainment through alcohol, he sticks firmly to his human identity, never understanding why someone would wish to be somebody else. While his passivity is the underlying cause of the metamorphoses, helping promote the climate of irresponsibility and indifference, it is his recognition of life as an absurdity that prompts him to change his character, rather than accept the presence of the rhinos. Yet he remains indecisive nearly to the very end, losing his faith in humanity and finding the rhinoceroses beautiful. His transformation and metamorphosis is a journey from conformity to non-conformity. When all are changed to animal state and he is alone, he wishes to be like them. He sympathezis with them.

My skin is so slack. I can't stand this white, hairy body. Oh I'd love to have a hard skin in that wonderful dull green colour - a skin that looks decent naked without any hair on it, like theirs! [He listens to the trumpetings!] Their song is charming —a bit raucous perhaps, but it does have charm! I wish I could do it I [He tries to imitate them!] Ahh, Ahh, Brr! No, that's not it I Try again, louder! Ahh, Ahh, Brr I No, that's not it, it's too feeble, it's got no drive behind it. Tm not trumpeting at all; Tm just howling. Ahh, Ahh, Brr. There's a big difference between howling and trumpeting. I've only myself to blame; I should have gone with them while there was still time. Now it's too late! Now Tm a monster, just a monster.(Ianesco: 107)

\footnotetext{
${ }^{2}$ www.royalcourttheatre.com/files/.../220/Rhinoceros
} 
In the last line of the play, though, he upturns his weak will and his absence of responsibility by being determined to protect and maintain humanity against the oppression of the rhinos.

Berenger's decision, however, is not completely unexpected. His love of Daisy discloses he has emotive and passionate wishes and longings for another human being. At one point, when it seems to him that he and Daisy will be united without regard for their co-worker Dudard's departure and transformation, Berenger believes that happiness is such a narcissistic thing!" Nevertheless his yearnings turn out not to be so egotistical and narcissistic. Even after Daisy leaves him in order for her to become a rhino, and after other friends abuse him and do the same, he feels remorseful for treating them unfairly, although they would have changed without him. He does not love Daisy only; he admires humanity, and is eager to take responsibility for its destiny. This determination of responsibility, rather than the motivation of power which the other characters considers dearly, is what at the end of the play stimulates Berenger's concluding line of resistance, "I'm not capitulating!"

Perhape one is to ask the question why doesn't Berenger change into a rhinoceros like others? The answer lies in the transformation of Berenger from an indifferent, intoxicating, and ennui- ridden man into the savior of humanity. This is in fact an idea of absurdism too which comprises the school to which the play belongs that one must commit oneself to an important cause in order to make a difference in life. Although through the play Berenger's need is to belong to people and feel at home which should really make him a front runner for rhinocification, he does not conform because he has a concern which he cannot express, which leads to low self-confidence and alcohol abuse. He doesn't contemplate that he is good enough for the people he admires or esteems. Since he has a deep rooted need to interrogate his existence, he can't find an instant method to sympathize with these rhinoceroses. He is not dreadfully involved in the first appearance of the animals. He is very slow to develop opinions about them. He is free from dogma and belief because he is constantly questioning everything. He has a goodness in him which gives him a certainty about the way he behaves.

$\mathrm{He}$ is a victim to the collective unconscious and circumstances of others. It is actually their collective unconscious which is dead set against change and is in favor of conformity. In certain cultures people resist non-conformity. In Judaism, people are encouraged to accept it, for example if somebody slaps a Jew in the face he will bring his other side of the face to receive another. This is within the collective conscious of many countries, in our culture, parent advises us not to quarrel with others and accept the status quo and say nothing. Berenger is in fact in such a situation. He is like an odd person among many familiar faces. He is a non-conformist like the writer himself. Even he is questioning the collective unconscious of the people and he is happy that he does not belong to this collective unconscious and this lack of belonging to this collective unconscious victimizes him and he is unable to grow in such a culture. This society becomes like a garden full of weeds. He girds his loin up against a sea of troubles to set it right. Berenger has to exercise more will-power and not surrender to life's pressures, like other characters, such as Dudard who seems to do just that as they control their own destinies. Berenger has to maintain a steadfast and determinate sense of responsibility which he does at the very end of the play. He is a savior of the whole world. When all are animals except him and Daisy he has a conversation with her in order to save the world like Adam and Eve:

BERENGER: Listen, Daisy, there is something we can do. We'll have children, and our children will have children-it'll take time, but together we can regenerate the human race.

DAISY: Regenerate the human race?

BERENGER: It happened once before.

DAISY: Ages ago. Adam and Eve ... They had a lot of courage.

BERENGER: And we, too, can have courage. We don't need all

that much. It happens automatically with time and patience.

DAISY: What's the use?

BERENGER: Of course we can-with a little bit of courage. 
DAISY: I don't want to have children-it's a bore.

BERENGER: How can we save the world, if you don't?

DAISY: Why bother to save it?(Ionesco, 102)

This conversation is revealing. He wants to save first Daisy and himself and second to create and regenerate human race. But Daisy does not accept his suggestion and leaves him. She calls him very presumptuous. Berenger offers her his love as the sign of his being right. Daisy in response to what Berenger offers as love says 'I feel a bit ashamed of what you call love-this morbid feeling, this male weakness. And female, too. It just doesn't compare with the ardour and the tremendous energy emanating from all these creatures around us'(Ionesco, 103). Berenger slaps her in the face. She defends the rhinoceroses saying 'they are stronger .... they are like gods'. Love cannot solve the problem. His Daisy is not "a true companion" (Bloom, 135). He is a real victim to the collective unconscious and mass's lack of understanding. She like the mass of the people of the society changes into a rhino. This the metamorphosis is an ailment, and "rhinoceritis" becomes a dominant metaphor for fascism as a spreadable, half-logical, half-ridiculous contamination of mind and morality. Ionesco offers imaginable, even benevolent reasons for why rhinoceritis spreads so quickly, refusing to settle on the normally approved claim of human violence. Monica Zutshi in the article 'Who's Afraid of Humans?: Absurdity and Affirmation in Eugène Ionesco's Rhinoceros' argues "Berenger is the only one who apprehends an ontological angst"(2013:1).

\section{CONCLUION}

There is a clash between personal consciousness and collective consciousness in the play. Berenger stands for the personal consciousness(individualism) and the other characters, the mass stand for the collective consciousness. Berenger is a victim of the circumstances since he has a personal cause to fight for and this makes him a hero at the end of the play. The play implicitly teaches us if we agree with Berenger we are Berenger-like characters. If we do not agree with him, this will changes us to other rhinoceros like other characters in the play who do not have personal causes. Berenger wants to redress the balance by love he and Daisy realize that they are left completely alone - the only humans left in a world of monsters. Berenger professes his love for Daisy and she seems to return his love. They try, though momentarily, to have a normal life amongst the rhinoceroses. After Berenger suggests that they attempt to regenerate the human race, Daisy begins to move away from him, signifying that Berenger doesn't appreciate love. She comes to believe the rhinoceroses are in the right - they who are strictly zealous. Berenger slaps Daisy without thinking, instantly asking for forgiveness from her realizing they have gone through many years of marriage in just a moment. They try to reunite, but are not successful. As Berenger inspects himself in a mirror for any sign of alteration, Daisy silently leaves to connect with the rhinoceroses. This is not the fault of Berenger that does not want to joint him to regenerate the race of human being. He is simply the victim of such collective way of thinking which go after their needs without regards for any humane feelings. Berenger is certainly a hero among the unheroic anmilistic creaturs who are looking for their own benefit. On the other hand, Berenger tries to hang on to his individuality always and reaps the results at the end.

Ionesco continues to criticize what he sees as an empty bourgeois, middle- class life. Berenger is stunned at Papillon's change only because Berenger notes that Papillon had such a good job to live for. His stunishment also discloses a paradox in Berenger's personality, showing the influential brainwashing that capitalism can enforce even on a person with an over-all consciousness of the barrenness of the workplace. Furthermore, the stagecraft helps intensify Ionesco's outlook. 


\section{References}

[1] Abrams, M.H. Harpham, Geoffrey Galt. A Glossory of literary terms. Eighth edition, new York: Hal, Richard and Winston Press, 1993.

[2] Bloom, Harold. Eugene Ionesco ed. Chelsea House Publishers. 2003.

[3] Ionesco, Eugene. Rhinoceros and other play. Trans. Drek Prous. New York. Grove Press, 1960.

[4] Krapp, Kristine M. Psychologists and their theories for students. Cengage Gale, 2004.

[5] Valentine, John M. "Kitsch and the Absurd in Eugène Ionesco's Rhinoceros."Florida Philosophical Review 10.1 (2011): 54.

[6] Zutshi, Monica. "Who's Afraid of Humans?: Absurdity and Affirmation in Eugène Ionesco's Rhinoceros." 